or minutes, the relative position of the hands on the dial probably at once sufficiently indicating the time to most persons without any need of reference thereto, but it would be by no means so easy to pick up the hour from a circle containing twenty-four, and especially in the case of public and turret clocks. There is also the question of change of the motion-work to which allusion has been already made-necessary if the hour-hand is to make one revolution only in twentyfour hours - a practical question in regard to which the watch- or clock-maker could probably best speak.

There is another way of adapting ordinary watches and clocks to the twenty-four hour system, which, if the watch is intended only for the reckoning of local time, seems deserving of consideration. It consists in making the hour figures shorter, not necessarily at all less distinct, and placing two circles of figures round the dial, an inner circle with hours from $O$ to $I I$, and an outer circle with hours from 12 to 23 . The hour-hand would thus point to $I$ and $I 3$ and to 2 and 14 , \&c., at the same time, it being understood that the hours $0,1,2$, \&c., would be reckoned in the morning, and the hours I2, I3, I4, \&c. in the afternoon, a convention to which people would probably soon accommodate themselves. On such a plan a watch would only require a new dial, no change of wheelwork being necessary, so that it could be very readily applied to existing watches, and so sooner promote the use of the twenty-four hour system. Persons might perhaps object to the introduction of two hour-circles from an artistic point of view. But, after all is said, the question whether one circle containing twenty-four hours, or two circles having twelve hours in each, be preferable, is one to be settled only by a consideration of the relative advantages and disadvantages of the two proposals, in regard to which it would be interesting to learn what business men and others on the one hand, and practical watchmakers on the other, may have to say. There are conditions under which the one circle of twenty-four hours would certainly be the more advantageous, and clearly it would be well that one system only should if possible be used.

As regards clocks, there is the further question of striking the hours. For public clocks we could not go on to twenty-four. It may be a question whether in large towns one stroke only at each hour might not be a suffi cient indication, though even this rule probably could hardly be universally applied.

\section{THE BRITISH ASSOCIATION FOR THE ADVANCEMENT OF SCIENCE}

$A^{\mathrm{T}}$ a meeting of the General Committee of the British Association held at the Royal Institution on the I I th instant, Sir Lyon Playfair was elected President for the meeting at Aberdeen next yexr. It was resolved to request the following to accept the office of Vice-President for that meeting :- The Duke of Argyll, the Duke of Richmond and Gordon, the Earl of Aberdeen, the Earl of Crawford and Balcarres, Sir William Thomson, James Matthews, Lord Provost of Aberdeen, Dr. Alexander Bain, Lord Rector of the University of Aberdeen, the Very Rev. Principal Pirie, and Prof. W. H. Flower. The following were elected Local Secretaries: I'rof. G. Pirie, Dr. Angus Fraser, and Mr. J. W. Crombie; Local Treasurers: Messrs. Robert Lumsden and John Findlater. The following appointments were also made:-General Treasurer: Prof. A. W. Williamson, Ph.D., F.R.S.; Genera Secretaries: Capt. Douglas Galton, C.B., F.R S., and A. G. Vernon Harcourt, F.R.S. ; Secretary: Prof. Bonney, D.Sc., F.R.S. ; Ordinary Members of the Council: Capt. W. de W. Abney, Prof. W. G. Adams, Prof. R. S. Ball, J. F. La Trobe Bateman, Sir F. J. Bramwell, Prof. W. Boyd Dawkins, Dr. Warren De La Rue, Prof. J. Dewar, Capt. Sir F. J. Evans, Prof. W. H. Flower, Dr. J. H.
Gladstone, J. W. L. Glaisher, Lieut.-Col. H. H. GodwinAusten, J. Clarke Hawkshaw, Prof. (). Henrici, Prof. T McK. Hughes, Dr. J. Gwyn Jeffreys, Prof. H. N. Moseley, Admiral Sir E. Ommanney, W. Pengelly, Dr. W. H. Perkin, Prof. Prestwich, the Right Hon. George SclaterBooth, Dr. H. C. Sorby, Sir R. Temple ; Auditors : John Evans, D.C.L., Treas.R.S., Dr. Huggins, F.R.S., and George Griffith, M.A.

Invitations for the year 1886 were received from Birmingham, Bournemouth, and Manchester, and after a discussion (in which the representatives of Manchester expressed their willingness to withdraw in favour of Birmingham for the year I 886 , but their earnest hope that the Association would not fail to visit them in 1887 ), it was agreed, nem con., to accept the invitation from the town of Birmingham for the year i 886 .

The report of the Council relating to the rules concerning the representation of local scientific societies at the meetings of the Association and the establishment of a Permanent Committee as a means of union between them and the Association were sanctioned, and it was resolved in accordance with a recommendation from the Council to present the die for the medal which is about to be founded at McGill University, Montreal, in commemoration of the visit of the Association to Montreal.

THE NEW VOLCANIC ISLAND OFF ICELAND $A \mathrm{~T}$ the end of July this year the light-keeper at Cape Reykjanes, the south-west point of Iceland, reported that a volcanic island had risen in the sea a few miles off the cape. Reykjanes has long been noted as a centre of volcanic activity, and from time to time islands have arisen and submarine eruptions have occurred in its neighbourhood. In the year of the great Skaptárfell eruption, which proved so fatal to Iceland, 1783, an island appeared off Reykjanes, only to disappear again after a very brief existence. Only a year or two ago an eruption of considerable violence occurred in the sea, not far from the spot where the new island appeared. Columns of steam and clouds of dust, mingled with occasional glowing masses of fused rock, were seen to rise out of the sea, and large quantities of pumice were thrown up and drifted ashore on the neighbouring coast.

Being desirous to learn as much as possible about the new island, I visited Reykjanes on September 9. The cape, like the greater part of the surrounding district, is entirely covered with lava; not far from the sea lie a number of boiling pools of considerable size, from whose agitated muddy waters arise the columns of steam that give the cape its name, Reykjanes (Smoking Cape) ; over a large area surrounding the pools the earth is perforated by steam jets and small mud boilers, and the traveller must pass warily over its treacherous surface, for under the thin and yielding upper crust lie beds of soft manycoloured clays, boiling hot, permeated by steam and mixed with sulphur. On a projecting cliff about I 50 feet high stands the lighthouse, a low octagonal stone house, and from the point a line of islands, four in number, runs out to the south-west, the nearest being about seven miles, and the farthest about sixteen miles, from the cape. Of these only the nearest two, Eldey or Melsækken (the Meal-sack, so called from the guano deposits that whiten the top of its bleak cylindrical mass), and Eldeyjardrangur, are usually visible from the lighthouse. The farther two, Geirfuglasker and Geirfugladrangur, are chiefly interesting as having been formerly frequented by the Great Auk or Gare-fowl (Alia impennis), now apparently extinct.

When I reached Reykjanes, rain and mist obscured the sea, Eldey could only with difficulty be seen, and the new island was quite invisible. I waited patiently for better weather, employing the time in examining the boiling springs and hot clay-beds, which are similar to 
those of the Krísurík sulphur mines, and the so-called "porcelain rock," a bed of very pure, white, and compact siliceous sinter or geyseritc, deposited by some long extinct boiling spring. It was not till the afternoon of the next day that the weather cleared up a little, and a long and patient watch from the top of a hill behind the light house was at length rewarded by the discovery of a dim spot on the horizon, which close observation through a good telescope showed to be the new island. It was quite invisible to the naked eye, but the light-keeper assured me that he had often seen it in clear weather, without a glass. When first seen, on July 29, its shape was that of a truncated cone with a slight depression on the top, and a considerable hollow half way down the slope on the north side.

On August 5 and 6 a series of violent earthquake shocks occurred, which shook and split the masonry of the lighthouse and damaged the lamps. For several days the new island was obscured by mist and rain, and when it again became visible its shape was considerably altered a large part of the slope on the south side had slipped down into the sea, where it now lies, forming two little hillocks close to the foot of the main mass, and leaving a steep face nearly perpendicular towards the bottom. On the north side there is shoal water extending some distance from the island. The length of the island is about one-

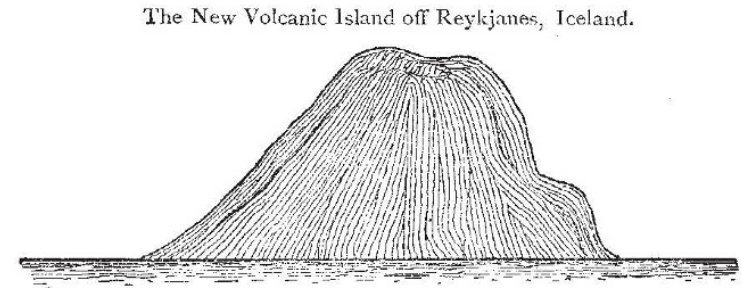

The island as when first seen,

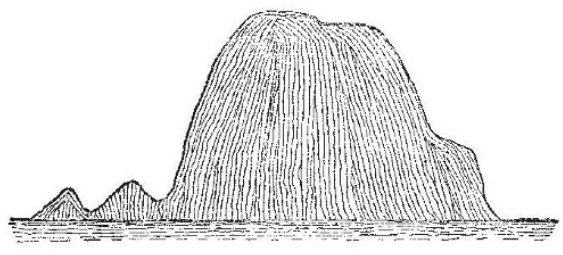

The island as it now appears.

third greater than its height. It lies nearly west-southwest of Reykjanes, and considerably to the north-west of Eldey. Two French naval officers who visited Reykjancs and made observations of the island about a fortnight before I arrived there, estimate its distance from the coast at nine or ten miles, but I believe it to be considerably greater. When first seen the island was perfectly black, but now the light-keeper tells me he can in clear weather distinguish by the aid of his glass a perceptible whitening of the upper part, due no doubt to the droppings of the myriads of sea-fowl which frequent the neighbouring islands and coast, and have apparently at once taken possession of the new island.

It is a singular fact that none of the ustal volcanic manifestations seem to have announced or accompanied the rise of the new island; no earthquakes were felt, no smoke or fire seen, and no pumice found floating on the sea. The island seems to have risen calmly and silently, without a soul being aware of its appearance, till, on July 29 , the light-keeper happening to look out to seaward, discovered it. For aught that any one knows to the contrary, it may have been there for many days before he happened to see it. No one has yet visited the island itself; the sea off Rekjanes is almost always rough, and the currents are very strong round the cape; the islands are surrounded by shoals and reefs; landing is at all times difficult and dangerous, even in the best weather, and quite impossible if the sea is at all disturbed; and as, since the discovery of the island, the weather has been for the most part stormy, intending explorers have been deterred by the dangers of the passage. Singularly enough, a French war-vessel and a Danish gun-boat which passed Reykjanes shortly before my visit failed to sec the new island. From the direction in which the new island lies, and its apparent distance from the coast, I am inclined to think that it must lie near to the Geirfuglasker (Gare-fowl Skerry), one of the four islands above mentioned, which lies somewhat to the north-west of the line formed by the other three, and which, being low and flat, cannot be seen from Reykjanes. It is not impossible that the new island is merely an addition to or upheaval of the old Geirfuglasker, which, by heightening it so as to make it visible from the shore, would produce the impression that a new island had risen. This view is held by some of the fishermen on the coast who are familiar with the islands, but the point cannot be definitely settled till the island is visited.

W. G. SPENCE PATERson,

British Consulate, Reykjavík, September 27

\section{TELESCOPES FOR ASTRONOMICAL PHOTOGRAPHY}

\section{I.}

BEFORE giving any suggestions as to the best kind of telescope to use, and the best methods to follow in the application of photography to astronomical observation and record, it may be more convenient to mention briefly what can be done in this way, particularly as the subject will be new to many who have not followed closely what has been recently done.

I wish to mention (I) That photography has now shown itself to be capable of giving us pictures of nebulæ that are superior to those made by eye and hand. (2) That anything that can be seen by the eye with a telescope of a certain size can be photographed, and, further than this, stars that are too faint to be seen in this telescope can yet be photographed by it with sufficient exposure. (3) That portions of the heavens of several degrecs extent each way can bc photographed, and stars therein of a magnitude smaller than that shown on the best existing charts or maps, pictured in their proper relative positions and magnitudes in a quicker, better, and more accurate manner than by the plan hitherto used. (4) That it is possible thus to make a complete serics of such pictures embracing the whole heavens, that will be practically free from human error. (5) That each individual nebula, cluster, or group of stars, can also be taken on as large a scale as possible, and form a supplement to the picture-maps on the smaller scale. (6) That though such pictures may differ slightly from the eye observations, owing to the different colours of light not affecting the eye and the sensitive plate in the same manner, they would have the cnormous advantage that they could be compared directly with other pictures, taken, after the lapse of any number of years, under conditions that there would be no difficulty in making almost identical. (7) That there are other applications of this new power, as in direct enlargements of the surface of the moon piece by piece, of the planets, of double stars, and close clusters, and indirectly in the discovery of planets, either major or minor, by the simple process of direct comparison of star pictures taken at intervals, when the actual position of a planet will be recorded at each date. If there be a planet beyond Neptune, such a plan as this is perhaps the only way to detect it, especially if it is now near the Milky Way, where stars of its probable magnitude cluster so thickly that no process other than this could be used to chart the stars and detect movement. If these things can be done, and I most 